\title{
Conivaptan: Evidence supporting its therapeutic use in hyponatremia
}

This article was published in the following Dove Press journal:

Core Evidence

24 June 2009

Number of times this article has been viewed

\section{Melissa $\mathrm{Li}-\mathrm{Ng}$ Joseph G Verbalis}

Division of Endocrinology and Metabolism, Georgetown University Medical Center, Washington, DC, USA
Correspondence: Joseph G Verbalis Professor of Medicine and Endocrinology, and Chief, Endocrinology and Metabolism, Division of Endocrinology and

Metabolism, Georgetown University Medical Center, Building D, Suite 232, 4000 Reservoir Road NW, Washington, DC 20007, USA

Email verbalis@georgetown.edu
Introduction: The available treatment options for euvolemic and hypervolemic hyponatremia are limited, and consist mainly of fluid restriction, diuresis, or hypertonic solutions. Most of these therapies are neither well tolerated nor totally effective, and many are associated with significant adverse effects. Vasopressin receptor antagonists, also known as vaptans, are a new class of agents that now offer an additional treatment option for hyponatremic patients. Conivaptan hydrochloride, a competitive antagonist of vasopressin V1a and V2 receptors, is the first agent in this class to be approved for treatment of euvolemic and hypervolemic hyponatremia in hospitalized patients.

Aims: This review critically assesses the evidence that support the use of conivaptan for the treatment of patients with euvolemic and hypervolemic hyponatremia.

Evidence review conclusion: Conivaptan is effective in raising serum sodium levels in a predictable and safe fashion in euvolemic and hypervolemic hyponatremic patients. Conivaptan provides the first molecularly targeted approach for correcting hyponatremia in hospitalized patients.

Keywords: Conivaptan hydrochloride, arginine vasopressin (AVP), hyponatremia, arginine vasopressin (AVP) receptor antagonist

Core evidence proof of concept summary table for conivaptan in hyponatremia

\begin{tabular}{|ll|}
\hline Outcome measure & Emerging evidence \\
\hline $\begin{array}{l}\text { Increased serum sodium levels } \\
\text { in patients with euvolemic and }\end{array}$ & Conivaptan is effective in raising serum sodium \\
levels safely in $70 \%-80 \%$ of treated patients.
\end{tabular}

hypervolemic hyponatremia.

Increased serum sodium levels

in patients with hypovolemic

hyponatremia.

Increased urine output due to

aquaresis.

Decreased requirement for fluid restriction.

Although effective at increasing serum sodium levels in hypovolemic hyponatremia, use of conivaptan is contraindicated in such patients because of potential worsening of the volume depletion. Dose-dependent increases in urine output and free water clearance are observed with increasing conivaptan doses, particularly in the first 24-48 hours of therapy.

The aquaresis associated with conivaptan use should decrease the severity of required fluid restriction; this has been documented with the selective V2R antagonist tolvaptan, but has not been studied with conivaptan.

Improved QOL in patients with The long-term effect of conivaptan on $\mathrm{QOL}$ is under investigation; studies with the selective $V 2 R$ antagonist tolvaptan have documented clinically relevant improvements in symptoms using the SF-I 2 patient self-assessment scale.

(Continued) 


\begin{tabular}{|c|c|}
\hline $\begin{array}{l}\text { (Continued) } \\
\text { Outcome measure }\end{array}$ & Emerging evidence \\
\hline $\begin{array}{l}\text { Improved respiratory symptoms in } \\
\text { hyponatremic patients with Class III } \\
\text { or IV heart failure. }\end{array}$ & $\begin{array}{l}\text { Conivaptan has not been shown to improve the } \\
\text { severity of respiratory symptoms in patients with } \\
\text { heart failure in short-term studies. Longer-term } \\
\text { studies are in progress. }\end{array}$ \\
\hline $\begin{array}{l}\text { Improved functional capacity in } \\
\text { patients with heart failure. }\end{array}$ & $\begin{array}{l}\text { The effect of conivaptan on functional capacity is } \\
\text { under investigation. }\end{array}$ \\
\hline $\begin{array}{l}\text { Decreased length of hospital stay } \\
\text { and resource utilization in hypona- } \\
\text { tremic patients. }\end{array}$ & $\begin{array}{l}\text { Despite theoretical predicted improvements in } \\
\text { length of hospital and ICU stay and corresponding } \\
\text { decreases in resource utilization with use of } \\
\text { conivaptan and other vaptans in hyponatremic } \\
\text { patients, no study to date has been performed to } \\
\text { assess this. }\end{array}$ \\
\hline
\end{tabular}

Arginine vasopressin (AVP) is a nonpeptide that is synthesized in the neurohypophyseal magnocellular neurons of the supraoptic and paraventricular nuclei of the hypothalamus. The synthesized AVP prohormone is packaged into neurosecretory granules and then transported down the supraopticohypophyseal tract to the posterior pituitary. During transport, pro-vasopressin is enzymatically cleaved into AVP, neurophysin, and a C-terminal glycopeptide. When release is stimulated, the circulating AVP binds to AVP V2 receptors on the principal cells of the collecting duct of the kidney, activating a cyclic AMP-mediated signal transduction pathway that stimulates insertion of aquaporin-2 (AQP2) water channels into the apical membrane of the principal cells. ${ }^{1}$ The AQP2 channels lead to increased permeability of the renal collecting duct and reabsorption of water along osmotic gradients, thereby producing an antidiuresis. Under normal conditions, AVP secretion is closely regulated to maintain body water homeostasis. Thus, during conditions of hypertonicity or volume depletion, AVP secretion is stimulated resulting in renal reabsorption of water and excretion of a concentrated urine by the kidneys. Conversely, during conditions of hypotonicity, AVP secretion is suppressed, leading to excretion of dilute urine by the kidneys. ${ }^{2}$

Hyponatremia is most often caused by inappropriately elevated plasma AVP levels, as epitomized by the syndrome of inappropriate secretion of antidiuretic hormone secretion (SIADH), which is caused by continued secretion of AVP despite plasma hypotonicity, leading to water retention and a dilutional decrease in serum sodium levels. ${ }^{3,4}$ The causes of SIADH are legion, including neoplasms, a variety of central nervous system and pulmonary disorders, and multiple drugs. Hyponatremia is the most common electrolyte disorder of hospitalized adult patients. When hyponatremia is defined as a serum sodium less than $135 \mathrm{mmol} / \mathrm{L}$, incidences of $6 \%$ to $22 \%$ have been reported. ${ }^{5,6}$ It is a serious electrolyte abnormality, which has been associated with high mortality among patients across a broad range of underlying conditions. Mortality rates in critically ill patients with symptomatic hyponatremia have been reported to be 60 -fold higher than in patients without hyponatremia. ${ }^{7}$

The available treatment options for euvolemic and hypervolemic hyponatremia are limited, and consist of diuresis, fluid restriction, or hypertonic solutions. Most of these therapies are neither well tolerated nor totally effective, and many are associated with significant adverse effects. ${ }^{7}$ The most recent approach to management of hyponatremia is the development of a new class of medications that are antagonists to the vasopressin V2 receptor, which are called "vaptans" because of the suffix applied to the generic names of these agents. Vaptans correct hyponatremia by blocking the binding of AVP to V2 receptors in the kidney, thereby preventing AVP-mediated water reabsorption. Several AVP receptor antagonists have been developed for clinical use, for use in hyponatremia, including conivaptan (YM-087), lixivaptan (VPA-985), satavaptan (SR-121463), and tolvaptan (OPC-41060). All four of these agents increase urine volume and decrease urine osmolality, but have no appreciable effects on urine sodium or potassium excretion. ${ }^{8}$ Conivaptan (Vaprisol ${ }^{\circledR}$; Astellas Pharma US, Inc., Deerfield, IL. USA) was originally developed by Yamanouchi Pharmaceuticals (Tokyo, Japan), and is the first medication of this class to be approved by the US Food and Drug Administration (FDA) for treating euvolemic hyponatremia in a setting of SIADH, hypothyroidism, adrenal insufficiency, or pulmonary disorders in hospitalized patients. ${ }^{9}$ Conivaptan later also received FDA-approved labeling for the treatment of 
hypervolemic hyponatremia in hospitalized patients. This article critically reviews the evidence supporting the use of conivaptan in the treatment of euvolemic and hypervolemic hyponatremia in hospitalized patients.

\section{Mechanism of action}

Conivaptan is a nonpeptide antagonist with a high affinity for the human vasopressin receptor subtypes V1a and V2. The other vaptans mentioned earlier, lixivaptan, satavaptan, and tolvaptan, are selective V2 receptor antagonists, and do not have appreciable binding to the V1a receptors. Three subtypes of AVP receptors (AVPR) have been identified. The V1a receptor (V1aR) is ubiquitous and is located on the vascular smooth muscle cells, hepatocytes and platelets. Stimulation of V1aR results in vasoconstriction, glycogenolysis, and platelet aggregation. The $\mathrm{V} 1 \mathrm{~b}$ receptor (V1bR) is found in the pituitary, where it mediates the release of adrenocorticotropic hormone (ACTH) in conjunction with corticotrophin-releasing hormone (CRH). The $\mathrm{V} 2$ receptor (V2R) is located primarily in the kidney, where it mediates antidiuresis. ${ }^{4}$ The major pharmacological effect of conivap$\tan$ in hyponatremia is accomplished by potent antagonism of V2R. As mentioned earlier, the V2R are functionally coupled to aquaporin-2 channels in the apical membrane of the collecting ducts of the kidney. Antagonism of V2R in the collecting duct of the kidney results in an increase in free water excretion or effective water clearance, net fluid loss, increased urine output, and decreased urine osmolality. ${ }^{10}$ But unlike diuretic agents, conivaptan enhances free water excretion without significantly increasing renal excretion of sodium or potassium. Because of this basic difference, vaptans have been called "aquaretic" agents, ie, stimulating excretion of only water, to distinguish their renal effects from the increased solute and water excretion characteristically produced by diuretics.

\section{Drug formulation and dosing}

Conivaptan is available as an IV formulation in $4 \mathrm{~mL}$ ampoules containing $20 \mathrm{mg}$ of conivaptan hydrochloride. A loading dose of $20 \mathrm{mg}$ is administered through a large vein over 30 minutes, followed by a maintenance dose of 20-40 mg per day for up to four days by continuous infusion. Peripheral intravenous infusion sites should be changed every 24 hours to reduce common infusion site complications such as irritation and phlebitis resulting from the use of propylene glycol as a solvent in the ampules. A new formulation premixed in $100 \mathrm{ml}$ infusion bags was approved by the FDA in October 2008, which should reduce complications from infusion site reactions since this formulation does not include propylene glycol. Close monitoring of serum sodium and volume status (every 4-6 hrs) is recommended with dose adjustments as necessary to achieve desired correction rates of the serum sodium concentration. ${ }^{9}$ Clinical trials of oral conivaptan have been reported at doses ranging from 20 to $80 \mathrm{mg}$. However, further development of an oral formulation was discontinued due to effects at the cytochrome P450 isoenzyme 3A4 (CYP3A4), leading to potential prolongation of action of other drugs also metabolized by CYP3A4.

\section{Pharmacokinetics}

The pharmacokinetics of conivaptan have been studied in healthy and special populations using both the oral and the intravenous formulations. The peak diuretic effect of oral and intravenous conivaptan occurred between two to four hours, ${ }^{11-14}$ resulting in a seven-fold increase in urine flow rate and a decrease in urinary osmolality. The duration of aquaretic effect following single doses both orally and intravenously was 12 hours. ${ }^{11}$ Urine output returned to baseline value 12 hours following oral or intravenous administration of conivaptan. The effect of conivaptan on pulmonary capillary wedge pressure (PCWP) in patients with advanced heart failure was sustained for approximately eight hours following the administration of intravenous conivaptan, and PCWP remained below baseline values even after 12 hours. ${ }^{13}$ The pharmacokinetics of $40 \mathrm{mg} /$ day and $80 \mathrm{mg} /$ day of intravenous and oral conivaptan were nonlinear, because conivaptan inhibits its own metabolism at CYP3A4.

Conivaptan is metabolized by the liver by CYP3A4, thus it can interact with other drugs that are also metabolized by CYP3A4. Because of this, conivaptan is contraindicated with the concurrent use of other potent CYP3A4 inhibitors such as ketoconazole, itraconazole, clarithromycin, ritonavir, and indinavir. Most of the drug is excreted in the feces $(83 \%)$. The effects of hepatic or renal impairments on the pharmacokinetics of conivaptan have not been systematically evaluated.

\section{Clinical efficacy Hyponatremia}

Conivaptan's efficacy for the treatment of hyponatremia has been assessed in three randomized double-blinded, placebocontrolled clinical trials and one open-label nonrandomized study. The three randomized studies include one pivotal study with intravenous conivaptan and two trials using oral conivaptan; the non-randomized study used intravenous conivaptan. Phase III studies showed that conivaptan 
reliably increases the serum sodium concentration, beginning as early as one to two hours after administration. Serum sodium increases by 2 to $4 \mathrm{mmol} / \mathrm{L}$ within 5 hours and by 6 to $9 \mathrm{mmol} / \mathrm{L}$ within 24 hours after initiation of therapy at the 20-mg and 40-mg doses, respectively. In most patients, approximately $70 \%$, the serum sodium normalized over a four-day continuous infusion, with the greatest increase in serum sodium occurring during the first 24 to 48 hours of treatment. The primary efficacy endpoint in these studies was the mean change in serum sodium over the duration of treatment, as measured by the area under the serum sodium effect curve (AUC), corrected for baseline serum sodium. ${ }^{15-17}$

In the pivotal phase III trial conducted with IV conivaptan, ${ }^{17}$ 84 patients with euvolemic or hypervolemic hyponatremia (serum sodium 115-130 mEq/L) were randomized to receive conivaptan $40 \mathrm{mg} /$ day, $80 \mathrm{mg} /$ day or placebo for four days. The continuous infusion of conivaptan was preceded by a $20 \mathrm{mg}$ intravenous loading dose. Of 84 total patients included in the intention-to-treat analysis, 66 completed treatment. Both doses of conivaptan were associated with significant improvements in serum sodium compared to placebo as measured by both the primary and secondary efficacy endpoints (Table 1). All patients also received standard care treatments for hyponatremia, which primarily consisted of fluid restriction. This was not a strict fluid restriction, ie, $<2$ liters/day, because the primary goal was to prevent the patients on placebo from worsening, rather than as an active treatment for hyponatremia. A planned subgroup analysis of this trial was performed to evaluate the efficacy of intravenous conivaptan in patients with euvolemic hyponatremia. ${ }^{18}$
Fifty-six of the 84 patients analyzed in the trial were euvolemic. Conivaptan 40 and $80 \mathrm{mg} /$ day effectively raised mean serum sodium on the first day of treatment. The mean increase in serum sodium with conivaptan remained significantly greater than that with placebo at the end of the four-day treatment period. The placebo group did not demonstrate any significant changes in serum sodium concentration (Figure 1).

Of the two oral conivaptan trials, one has been published. ${ }^{16}$ The efficacy of oral conivaptan was evaluated in 74 euvolemic and hypervolemic hyponatremic patients who were randomized to receive oral conivaptan $40 \mathrm{mg} /$ day, $80 \mathrm{mg} /$ day, or placebo, all given in two divided doses/day for five days. Both doses of conivaptan were associated with significant dose-dependent improvements in serum sodium compared to placebo (Table 2). Results from the second oral conivaptan study are available in abstract form only. ${ }^{15}$ The study, similar to the other oral conivaptan study, included 83 patients with euvolemic and hypovolemic hyponatremia, and revealed the same dose-dependent increase in serum sodium concentrations (Table 2).

Results from the open-label multicenter trial using intravenous conivaptan were presented at the Annual Meeting of the Endocrine Society in June 2008. ${ }^{19}$ The study was conducted from February 2004 to June 2005, and included 251 hospitalized patients with euvolemic and hypervolemic hyponatremia to assess the efficacy and safety of intravenous conivaptan 20 and $40 \mathrm{mg}$ /day for four days and for up to 30 days after cessation of therapy. The most common underlying illness associated with hyponatremia was SIADH (43\% of patients).

Table I Efficacy results from the pivotal phase III intravenous conivaptan trial ${ }^{16}$

\begin{tabular}{|c|c|c|c|}
\hline & Placebo $(n=29)$ & $40 \mathrm{mg} /$ day $(\mathrm{n}=29)$ & $80 \mathrm{mg} /$ day $(\mathrm{n}=26)$ \\
\hline Baseline serum $\mathrm{Na}(\mathrm{mEq} / \mathrm{L})$ & $124.3 \pm 4$ & $123.3 \pm 4.7$ & $124.8 \pm 3.4$ \\
\hline \multicolumn{4}{|l|}{ Primary efficacy endpoint } \\
\hline $\begin{array}{l}\text { Change from baseline serum } \mathrm{Na} A U C \text { to day } 4 \\
\text { (LS mean } \pm \mathrm{SE} \text {, in } \mathrm{mEq} / \mathrm{L}-\mathrm{hr} \text { ) }\end{array}$ & $12.9 \pm 61.2$ & $490.9 * \pm 56.8$ & $716.6^{*} \pm 60.5$ \\
\hline \multicolumn{4}{|l|}{ Secondary efficacy endpoints } \\
\hline $\begin{array}{l}\text { Median time to serum } \mathrm{Na} \geq 4 \mathrm{mEq} / \mathrm{L} \text { increase } \\
\text { over baseline }[\mathrm{hrs}(95 \% \mathrm{Cl})]\end{array}$ & NE & $23.7 *(10-24)$ & $23.4 *(6-24)$ \\
\hline $\begin{array}{l}\text { Mean total time serum } \mathrm{Na} \geq 4 \mathrm{mEq} / \mathrm{L} \text { over } \\
\text { baseline (LS mean in hrs } \pm \mathrm{SE} \text { ) }\end{array}$ & 14.25 .3 & $53.2 * \pm 5.2$ & $72.7 * \pm 5.4$ \\
\hline $\begin{array}{l}\text { Mean change in serum } \mathrm{Na} \text { from baseline } \\
\text { to end of day } 4 \text { [LS mean in } \mathrm{mEq} / \mathrm{L} \pm \mathrm{SE} \\
\text { (\# of evaluable patients)] }\end{array}$ & $2 \pm 0.82(n=25)$ & $\begin{array}{l}6.8^{*} \pm 0.81 \\
(n=24)\end{array}$ & $9 * \pm 0.8(n=24)$ \\
\hline $\begin{array}{l}\text { Number of patients with } \geq 6 \mathrm{mEq} / \mathrm{L} \text { increase } \\
\text { in serum } \mathrm{Na} \text { or increase to normal serum } \mathrm{Na} \\
(\geq 135 \mathrm{mEq} / \mathrm{L})(\%)\end{array}$ & $6(2 I)$ & $20(69)^{*}$ & $23(89)^{*}$ \\
\hline
\end{tabular}

Notes: *Significant vs placebo.

Abbreviations: AUC, area under the curve; LS, least squares; NE, not estimable. 


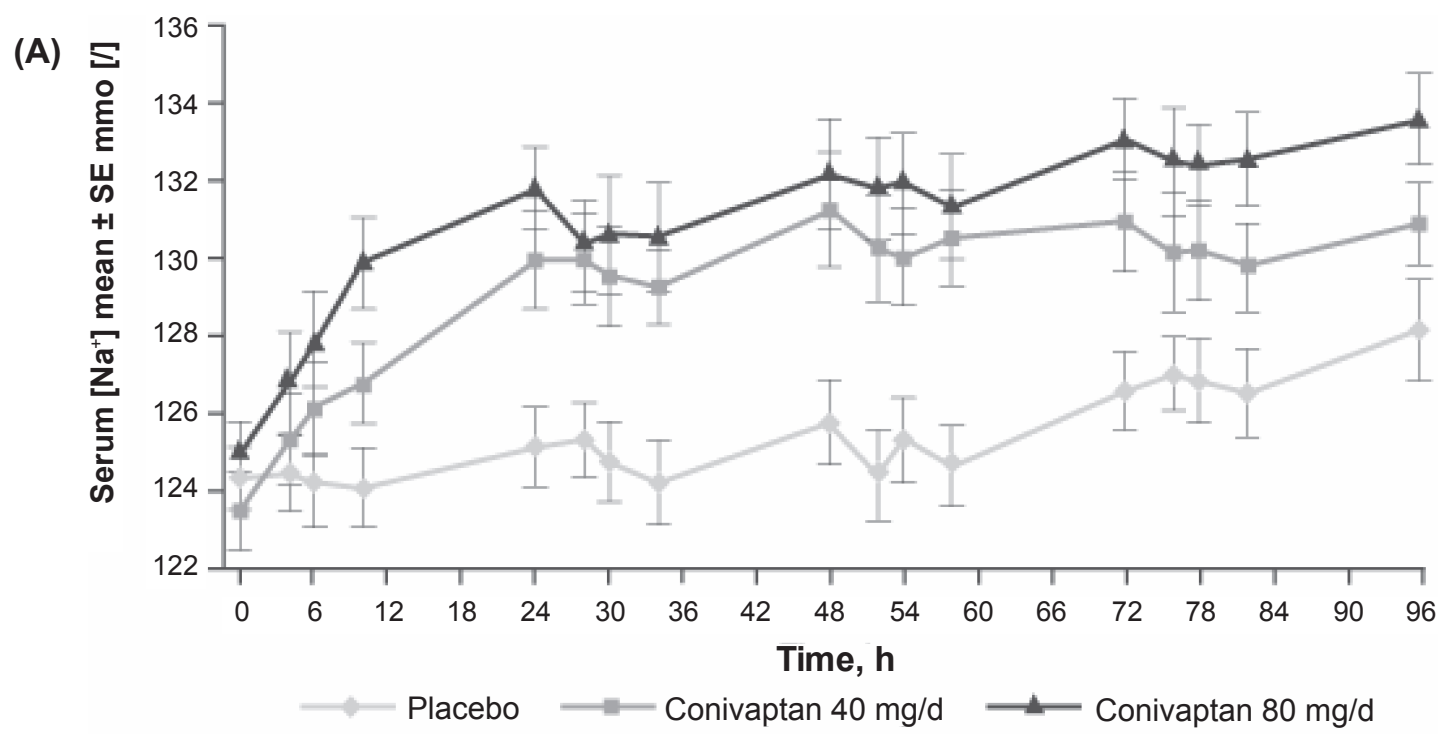

(B)

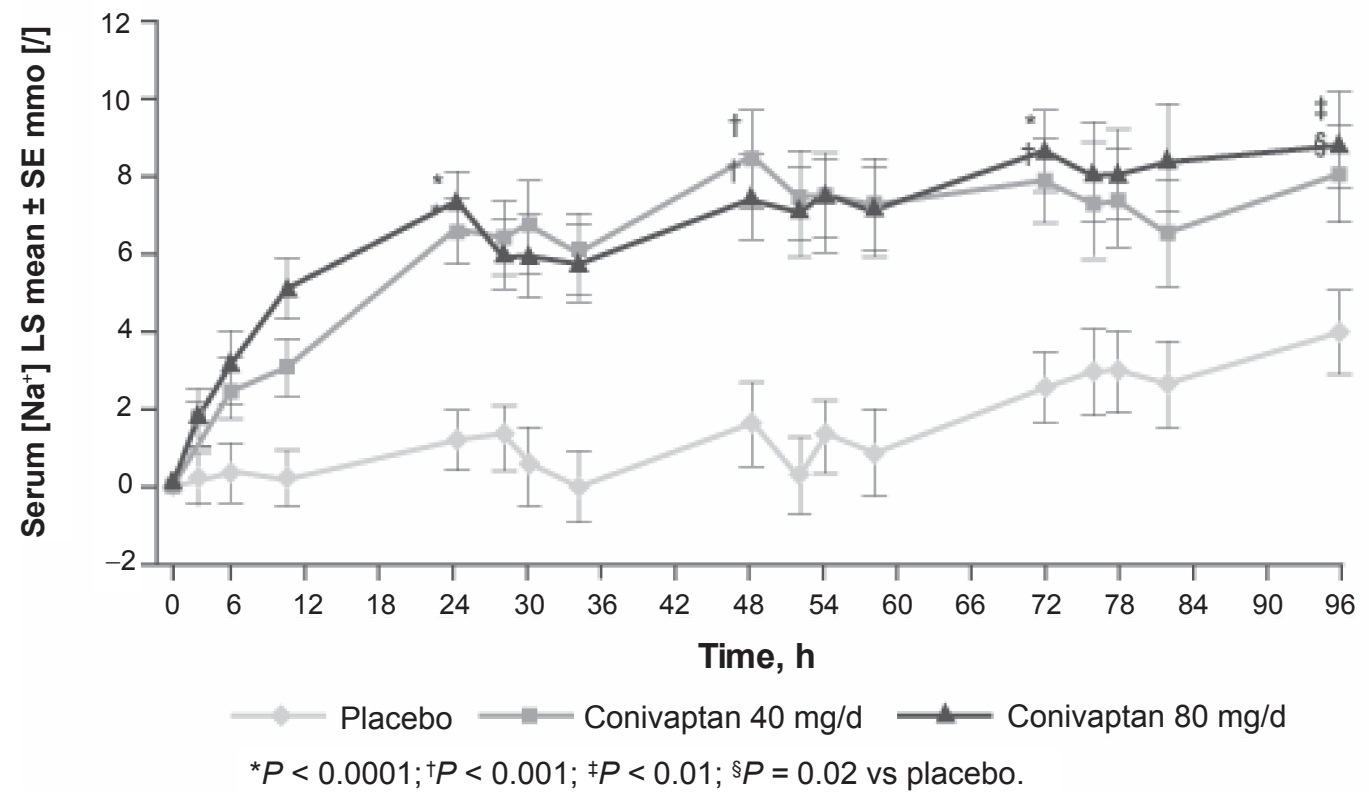

Figure I Mean (SE) serum $\left[\mathrm{Na}^{+}\right]$at baseline and during treatment $(\mathbf{A})$ and least-squares $(\mathrm{LS})$ mean change from baseline in serum [Na $\left.{ }^{+}\right]$during treatment $(\mathbf{B})$ in patients with euvolemic hyponatremia. ${ }^{18}$

Conivaptan was associated with significant increases in serum sodium concentration that were sustained throughout the study. At the cessation of active therapy, the mean serum sodium increased by 9.4 and $8.8 \mathrm{mEq} / \mathrm{L}$ in patients given conivaptan 20 and $40 \mathrm{mg} /$ day, respectively. The response did not appear to differ significantly among patients given 20 or $40 \mathrm{mg} /$ day. Very interestingly, the increases in serum sodium over baseline achieved through the end of treatment persisted through days 11 and 34 after initiation of aquaretic therapy even though the duration of active treatment was only four days. The reason for the persistence of the correction is unknown, but it suggests that limited infusions of conivaptan may be sufficient to improve hyponatremia not only during active treatment, but also for longer periods of time in patients who have improvement in their underlying comorbidities responsible for the hyponatremia.

\section{Heart failure}

Although conivaptan has been evaluated extensively in patients with congestive heart failure (CHF), efficacy has not been established other than for correction of hyponatremia; thus, conivaptan is not indicated for primary treatment of CHF at this time. Vasopressin levels are often elevated in patients with heart failure and left ventricular (LV) dysfunction, ${ }^{20}$ 
Table 2 Efficacy results from oral conivaptan trials ${ }^{14,15}$

\begin{tabular}{|c|c|c|c|c|c|c|}
\hline & \multicolumn{3}{|l|}{ Ghali et al } & \multicolumn{3}{|l|}{ Gross et al } \\
\hline & $\begin{array}{l}\text { Placebo } \\
(n=23)\end{array}$ & $\begin{array}{l}40 \mathrm{mg} / \text { day } \\
(\mathrm{n}=24)\end{array}$ & $\begin{array}{l}80 \mathrm{mg} / \mathrm{day} \\
(\mathrm{n}=27)\end{array}$ & $\begin{array}{l}\text { Placebo } \\
(n=30)\end{array}$ & $\begin{array}{l}40 \mathrm{mg} / \text { day } \\
(\mathrm{n}=27)\end{array}$ & $\begin{array}{l}80 \mathrm{mg} / \mathrm{day} \\
(\mathrm{n}=26)\end{array}$ \\
\hline Baseline serum $\mathrm{Na}(\mathrm{mEq} / \mathrm{L})$ & $123.4 \pm 4.1$ & $125.3 \pm 3.5$ & $125.4 \pm 4$ & $125.6 \pm 3.9$ & $|25.| \pm 5 . \mid$ & $125.6 \pm 3.6$ \\
\hline \multicolumn{7}{|l|}{ Primary efficacy endpoint } \\
\hline $\begin{array}{l}\text { Change from baseline serum Na AUC } \\
\text { to day } 5 \text { (LS mean } \pm \mathrm{SE} \text {, in } \mathrm{mEq} / \mathrm{L}-\mathrm{hr} \text { ) }\end{array}$ & $309.2 \pm 94.8$ & $621.3^{*} \pm 89$ & $836.2 * \pm 87.8$ & $87.5 \pm 80.8$ & $634.2 * \pm 84.2$ & $952.7^{*} \pm 85.7$ \\
\hline \multicolumn{7}{|l|}{ Secondary efficacy endpoints } \\
\hline $\begin{array}{l}\text { Median time to serum } \mathrm{Na} \geq 4 \mathrm{mEq} / \mathrm{L} \\
\text { increase over baseline }[\mathrm{hrs}(95 \% \mathrm{Cl})]\end{array}$ & 71.7 (49-NE) & $27.5 *(12-47)$ & $12.1 *(\mid I-28)$ & NE & $23.5 *(12-24)$ & $8.7 *(6-24)$ \\
\hline $\begin{array}{l}\text { Mean total time serum } \mathrm{Na} \geq 4 \mathrm{mEq} / \mathrm{L} \\
\text { over baseline ( } \mathrm{LS} \text { mean in hrs } \pm \mathrm{SE} \text { ) }\end{array}$ & $46.5 \pm 9$ & $69.8^{*} \pm 8.5$ & $88.8^{*} \pm 8.4$ & $\mathrm{n} / \mathrm{a}$ & $\mathrm{n} / \mathrm{a}$ & $\mathrm{n} / \mathrm{a}$ \\
\hline $\begin{array}{l}\text { Mean change in serum Na from baseline } \\
\text { to end of day } 4 \text { [ } \mathrm{LS} \text { mean in } \mathrm{mEq} / \mathrm{L} \pm \mathrm{SE} \text { ] }\end{array}$ & $3.4 \pm 1.1$ & $6.4 \pm 1$ & $8.2 * \pm 1$ & $1 \pm 0.9$ & $6.8^{*} \pm 0.9$ & $8.8^{*} \pm 0.9$ \\
\hline $\begin{array}{l}\text { Number of patients with } \geq 6 \mathrm{mEq} / \mathrm{L} \\
\text { increase in serum } \mathrm{Na} \text { or increase to } \\
\text { normal serum } \mathrm{Na}(\geq 135 \mathrm{mEq} / \mathrm{L})(\%)\end{array}$ & II (48) & $17(7 \mid)$ & $22(82)^{*}$ & $6(20)$ & $18(67)^{*}$ & $23(89) *$ \\
\hline
\end{tabular}

Notes: Bioavailability of oral conivaptan is $\sim 30 \%$; *Significant vs placebo.

Abbreviations: NE, not estimable; LS, least squares; $n / a$, not available.

and they are clearly associated with adverse cardiovascular outcomes in the setting of LV dysfunction after myocardial infarction. ${ }^{21}$ These data suggest that vasopressin may contribute to the circulatory response in patients with heart failure, and may also play a role in the development and progression of heart failure. Combined V1aR/V2R antagonism with conivaptan therefore does offer a theoretical benefit in CHF. If systemic hemodynamic improvement occurs with V1aR antagonism, renal hemodynamics would improve as well with V2R antagonism, leading to a greater clinical benefit.

The hemodynamic effects of conivaptan were evaluated in a prospective, randomized, double-blind study of 142 patients with New York Heart Association (NYHA) Class III or IV heart failure of at least three months duration. ${ }^{13}$ Subjects were randomized to receive a single dose of intravenous (IV) conivaptan $(10,20$, or $40 \mathrm{mg})$ or placebo, administered over 30 minutes. Conivaptan produced favorable hemodynamic changes in patients with advanced heart failure, without affecting blood pressure or heart rate. Pulmonary capillary wedge pressure and right atrial pressure were significantly reduced in the conivaptan $20 \mathrm{mg}$ and $40 \mathrm{mg}$ groups at three to six hours post-dose as compared with the placebo groups. Urine output was significantly higher in the conivaptan-treated patients as compared with placebo, and dose-dependent increases in urine output were observed with increasing conivaptan doses $(p<0.001)$. Despite conivaptan's properties as a V1aR antagonist, it had no significant effects on systolic blood pressure and pulse rate. No statistically significant changes in cardiac index, mean arterial pressure, pulmonary artery pressure, systemic or pulmonary vascular resistance were observed among the treatment groups. Serum osmolality, serum sodium, and potassium levels were similar among conivaptan and placebo groups. Of note, the patients were fluid-restricted to $250 \mathrm{~mL}$ every two hours during the 12-hour study periods and background diuretics and other medications were held during the study period. It should be noted that this study only examined the acute alterations in hemodynamics following a single intravenous dose of conivaptan. Despite the encouraging results of this study, other pilot and phase II studies have not shown benefits in clinical outcomes with longer term conivaptan use.

In a double-blind, dose-ranging pilot study, ${ }^{22} 162$ hospitalized patients with NYHA Class III or IV heart failure were randomized to receive conivaptan $20 \mathrm{mg}$ by intravenous bolus followed by continuous infusion of $40 \mathrm{mg} /$ day, $80 \mathrm{mg} /$ day, $120 \mathrm{mg} /$ day, or placebo for two days. Efficacy endpoints included change in respiratory symptoms, urine output and weight. Ten patients in the conivaptan groups and one in the placebo group discontinued the drug due to adverse events. Significant increases in urine output and changes in body weight were observed with all doses of conivaptan compared to placebo, but conivaptan did not improve the severity of respiratory symptoms.

A Dose evaluation of Vasopressin ANtagonist in CHF patients undergoing Exercise (ADVANCE) was a multicenter, double-blind, placebo-controlled, randomized trial designed to investigate the effect of conivaptan on functional 
capacity in patients with heart failure. ${ }^{23}$ The study enrolled 345 patients with NYHA class II to IV symptoms who were being treated with standard pharmacotherapy for heart failure. Three oral doses of conivaptan were compared with placebo for 12 weeks. Currently, only the methodology of this trial has been published, but additional results are anticipated in the future.

\section{Tolerability}

Conivaptan was generally well tolerated with the majority of reactions being mild. The majority of adverse events were infusion site reactions during intravenous administration, likely as a result of propylene glycol, which is irritating to veins. These reactions occurred in over $50 \%$ of conivaptan patients compared with $2 \%$ of placebo-treated patients during clinical trials (Table 3). A new formulation pre-mixed in $100 \mathrm{ml}$ infusion bags was approved by the FDA in October 2008 , and should reduce infusion site complications since this formulation does not include propylene glycol. Infusion site reactions were the most common reason for discontinuation during clinical trials. Although most infusion site complications were minor, including local inflammation, phlebitis, and pain at the infusion site, some serious infusion site reactions did occur.

Other side effects in decreasing order included headaches, hypokalemia, thirst, vomiting, polyuria, peripheral edema, diarrhea, and orthostatic hypotension. Orthostatic hypotension generally occurred on days 1 and 2 of therapy, likely because of volume depletion from induced aquaresis. Although V1aR antagonism on vascular smooth muscle could contribute to hypotension as well, this is less likely because: (1) AVP is not necessary for blood pressure homeostasis, ${ }^{8}$ and (2) the orthostatic hypotension was mild, short lived, and did not result in withdrawal of patients from the studies.

Another safety concern that occurred in approximately $9 \%$ of the subjects during clinical trials was a too-rapid correction of serum sodium concentration with the administration of conivaptan. ${ }^{9}$ Overly rapid correction of severe hyponatremia can produce pontine and extrapontine myelinolysis, also called osmotic demyelination syndrome (ODS), a brain demyelinating disease that can cause substantial neurological morbidity and mortality. ${ }^{24}$ However, no cases of ODS were noted in any of the clinical trials, nor have been reported with subsequent clinical use of conivaptan since 2006. This is likely the result of using titrated doses of conivaptan with careful monitoring of the serum sodium concentrations during the active phase of correction, thereby achieving a controlled and limited correction of hyponatremia. ${ }^{4}$
Review of data from patients with adverse effects of hypokalemia revealed that the occurrence of a low serum potassium $<3.3 \mathrm{mEq} / \mathrm{L}$ (the protocol-defined low threshold for hypokalemia, normal reference range: $3.5-5.0 \mathrm{mEq} / \mathrm{L}$ ) at the end of days 2 and 4 was not nearly as high as the reported occurrence of hypokalemia adverse events. Overall changes from baseline in serum potassium during the four-day treatment period were mild, and did not reach a level of clinical significance.

\section{Clinical indications Hyponatremia}

Conivaptan is currently indicated for the treatment of euvolemic hyponatremia as a result of SIADH, pulmonary disorders, hypothyroidism or adrenal insufficiency, and for the treatment of hypervolemic hyponatremia. A panel of experts in hyponatremia evaluated the situations in which aquaretic agents should be considered for therapy. ${ }^{18}$ In hypovolemic hyponatremia, induced aquaresis would aggravate the underlying volume depletion. Consequently, conivaptan and all other vaptans are contraindicated in hypovolemic hyponatremia. For euvolemic hyponatremia, aquaretic agents will likely become a mainstay of treatment. However, careful clinical assessment of the patient and an accurate diagnosis of euvolemic hyponatremia are necessary before therapy is prescribed. In hypervolemic hyponatremia, antagonism of $\mathrm{V} 2 \mathrm{R}$ represents the best approach to treating hyponatremia in most edema-forming states such as congestive heart failure and cirrhosis, because excess AVP is the most important pathophysiological factor involved in the pathogenesis of hyponatremia under these conditions, and because therapies employing administration of sodium chloride are generally contraindicated in such patients.

\section{Potential therapeutic indications for conivaptan and similar agents Congestive heart failure}

Patients with CHF often do not correct hypo-osmolar hyponatremia with conventional diuretic therapy. However, reversing impaired free water excretion with conivaptan normalizes dilutional hyponatremia in congestive heart failure patients. ${ }^{4,17}$ Conivaptan and other V2R antagonists will likely prove to be superior to conventional diuretics in this setting, since they can induce free water diuresis without an accompanying solute diuresis. Tolvaptan, an oral V2R antagonist, has been assessed in several trials for the management of acute and chronic heart failure. The Acute 
Table 3 Adverse reactions occurring in $\geq 5 \%$ of patients or healthy volunteers during the pivotal phase III trial ${ }^{8}$

\begin{tabular}{|c|c|c|c|}
\hline Side effect & $\begin{array}{l}\text { Placebo }(n=69) \\
\text { N (\%) }\end{array}$ & $\begin{array}{l}20 \mathrm{mg}(\mathrm{n}=37) \\
\mathrm{N}(\%)\end{array}$ & $\begin{array}{l}40 \mathrm{mg}^{\mathrm{a}}(\mathrm{n}=315) \\
\mathrm{N}(\%)\end{array}$ \\
\hline \multicolumn{4}{|c|}{ Blood and lymphatic system disorders } \\
\hline Anemia NOS & $2(3 \%)$ & $2(5 \%)$ & $18(6 \%)$ \\
\hline \multicolumn{4}{|l|}{ Cardiac disorders } \\
\hline Atrial fibrillation & $0(0 \%)$ & $2(5 \%)$ & $7(2 \%)$ \\
\hline \multicolumn{4}{|l|}{ Gastrointestinal disorders } \\
\hline Constipation & $2(3 \%)$ & $3(8 \%)$ & $20(6 \%)$ \\
\hline Diarrhea NOS & $0(0 \%)$ & $0(0 \%)$ & $23(7 \%)$ \\
\hline Nausea & $3(4 \%)$ & I (3\%) & $17(5 \%)$ \\
\hline Vomiting NOS & $0(0 \%)$ & $2(5 \%)$ & $23(7 \%)$ \\
\hline \multicolumn{4}{|c|}{$\begin{array}{l}\text { General disorders and administration } \\
\text { site conditions }\end{array}$} \\
\hline Edema peripheral & I (I\%) & I (3\%) & $24(8 \%)$ \\
\hline Infusion site erythema & $0(0 \%)$ & $0(0 \%)$ & $18(6 \%)$ \\
\hline Infusion site pain & I (I\%) & $0(0 \%)$ & $16(5 \%)$ \\
\hline Infusion site phlebitis & I (I\%) & $19(51 \%)$ & $102(32 \%)$ \\
\hline Infusion site reaction & $0(0 \%)$ & $8(22 \%)$ & $61(19 \%)$ \\
\hline Pyrexia & $0(0 \%)$ & $4(11 \%)$ & $15(5 \%)$ \\
\hline Thirst & $\mathrm{I}(\mathrm{I} \%)$ & I (3\%) & $19(6 \%)$ \\
\hline \multicolumn{4}{|l|}{ Infections } \\
\hline Pneumonia NOS & $0(0 \%)$ & $2(5 \%)$ & $7(2 \%)$ \\
\hline Urinary tract infection NOS & $2(3 \%)$ & $2(5 \%)$ & $14(4 \%)$ \\
\hline \multicolumn{4}{|l|}{$\begin{array}{l}\text { Injury, poisoning and procedural } \\
\text { complications }\end{array}$} \\
\hline Post-procedural diarrhea & $0(0 \%)$ & $2(5 \%)$ & $0(0 \%)$ \\
\hline \multicolumn{4}{|l|}{ Investigations } \\
\hline ECG ST segment depression & $0(0 \%)$ & $2(5 \%)$ & $0(0 \%)$ \\
\hline \multicolumn{4}{|l|}{ Metabolism and nutrition disorders } \\
\hline Hypokalemia & $2(3 \%)$ & $8(22 \%)$ & $30(10 \%)$ \\
\hline Hypomagnesemia & $0(0 \%)$ & $2(5 \%)$ & $6(2 \%)$ \\
\hline Hyponatremia & $\mathrm{I}(\mathrm{l} \%)$ & $3(8 \%)$ & $20(6 \%)$ \\
\hline \multicolumn{4}{|l|}{ Nervous system disorders } \\
\hline Headache & $2(3 \%)$ & $3(8 \%)$ & $32(10 \%)$ \\
\hline \multicolumn{4}{|l|}{ Psychiatric disorders } \\
\hline Confusional state & $2(3 \%)$ & $0(0 \%)$ & $16(5 \%)$ \\
\hline Insomnia & $0(0 \%)$ & $2(5 \%)$ & $12(4 \%)$ \\
\hline \multicolumn{4}{|c|}{$\begin{array}{l}\text { Respiratory, thoracic and mediastinal } \\
\text { disorders }\end{array}$} \\
\hline Pharyngolaryngeal pain & $3(4 \%)$ & $2(5 \%)$ & $3(1 \%)$ \\
\hline \multicolumn{4}{|c|}{ Skin and subcutaneous tissue disorders } \\
\hline Pruritus & $0(0 \%)$ & $2(5 \%)$ & $2(1 \%)$ \\
\hline \multicolumn{4}{|l|}{ Vascular disorders } \\
\hline Hypertension NOS & $0(0 \%)$ & $3(8 \%)$ & $20(6 \%)$ \\
\hline Hypotension NOS & $2(3 \%)$ & $3(8 \%)$ & $16(5 \%)$ \\
\hline Orthostatic hypotension & $0(0 \%)$ & $5(14 \%)$ & $18(6 \%)$ \\
\hline
\end{tabular}

Notes: ${ }^{a}$ Although an intravenous dose of conivaptan $80 \mathrm{mg} /$ day was also studied, it was associated with a higher incidence of infusion site reactions and a higher rate of discontinuation due to adverse events than the $40 \mathrm{mg} /$ day dose. The maximum FDA-approved daily intravenous dose of conivaptan (following the loading dose) is $40 \mathrm{mg} /$ day. Abbreviations: ECG, electrocardiogram; NOS, not otherwise specified. 
and Chronic Therapeutic Impact of Vasopressin antagonist in Congestive Heart Failure (ACTIV in CHF) trial was a multicenter, randomized controlled trial with 319 patients with acute exacerbation of CHF. ${ }^{25} 21.3 \%$ of the patients had hyponatremia (serum sodium $<136 \mathrm{mEq} / \mathrm{L}$ ) at randomization. Patients were randomized to receive one of three doses of oral tolvaptan or placebo for up to 60 days in addition to standard CHF therapy. All tolvaptan groups had significant reductions in body weight compared with the placebo group and had significantly higher urine volumes than the placebo group. These differences persisted throughout the hospital stay. A large phase III multi-center trial, Efficacy of Vasopressin antagonist in hEart failuRE outcome Study with Tolvaptan (EVEREST), compared the short-term and long-term administration of tolvaptan with placebo in 4133 patients admitted with worsening heart failure. ${ }^{26,27}$ In the short-term study, tolvaptan patients lost more weight on day 1 and day 7 or on discharge. More patients receiving tolvaptan reported improvement in dyspnea on day 1 and reduction in edema on day 7 , whereas improvement in general clinical status did not differ between groups. ${ }^{25}$ However in the longterm study, with a median follow-up of 9.9 months, tolvaptan had no effect on long-term mortality or heart failure-related morbidity. ${ }^{27}$ Within the limitations inherent in this study, the long-standing association between adverse outcomes and hyponatremia in patients with CHF does not appear to be due to adverse effects of the hyponatremia itself. ${ }^{28}$

\section{Cirrhosis}

Patients with cirrhosis, intractable ascites, and peripheral edema are often ineffectively treated with aldosterone antagonists and beta-blockers, but it is currently not advisable to use conivaptan in patients with cirrhosis because V1aR inhibition may block the vasoconstrictive effects of AVP in the portal and splanchnic circulation, possibly increasing portal blood flow. However, decreases in portal hypertension may offset this effect. Consequently, the net effect of conivaptan on the risk of precipitating esophageal variceal bleeding is unknown. Theoretically, selective V2R antagonists should not entail adverse effects on portal hemodynamics, but their safety in cirrhosis remains to be ascertained. One of the other oral V2R antagonists, lixivaptan, has been studied in patients with cirrhosis. One randomized controlled trial of 44 hospitalized patients with stable hyponatremia that included 33 patients with cirrhosis showed that a seven-day course of lixivaptan was well tolerated and increased free water clearance, urine output and serum sodium concentrations in a dose-dependent manner. ${ }^{29}$ Another study of 60 patients with cirrhosis showed an increase in serum sodium concentration after seven days of treatment to a mean of $132 \mathrm{mEq} / \mathrm{L}$ compared with $126 \mathrm{mEq} / \mathrm{L}$ in the placebo group. ${ }^{30}$ Lixivaptan had no significant effects on blood pressure or heart rate.

\section{Long-term treatment of hyponatremia}

Most placebo-controlled studies using AVPR antagonists to treat hyponatremia have been of relatively short duration. However, recent data from two multicenter 30-day placebocontrolled trials of tolvaptan resulted in sustained correction of hyponatremia and improved cognitive function. ${ }^{31}$ Another study using satavaptan, an oral V2R antagonist, began as a five-day randomized, placebo-controlled trial in patients with SIADH and continued as an open-label trial which showed continued efficacy and good tolerance for up to 12 months of treatment. ${ }^{32}$ Under a fluid restriction of $<1500 \mathrm{~mL} /$ day, mean serum sodium levels remained within the normal range during the open-label period. Long-term response rates to oral conivaptan and other AVPR antagonists, and whether correction of chronic hyponatremia results in improved functional status and quality of life, will require additional studies.

\section{Conclusions}

Conivaptan, along with the other AVPR antagonists, produce an aquaretic effect by blocking the activity of endogenous AVP at the V2R, which improves dilutional hyponatremia. The current data indicate that these agents are highly effective in producing a safe and predictable aquaresis, thereby increasing serum sodium levels in hyponatremic patients. Conivaptan is the first AVPR antagonist to receive FDA approval, specifically for IV administration to hospitalized patients with euvolemic or hypervolemic hyponatremia. Several investigational oral V2R-selective AVPR antagonists are in late-stage clinical trials and hold promise for long-term therapy of chronic hyponatremia. The advent of these agents represents a significant achievement for the management of hyponatremia. However, the safe use of conivaptan and other aquaretics will require avoidance of their use in hypovolemic patients and caution with regard to the correction rate of hyponatremia. Clinicians must also be aware of drug interactions, particularly drugs that are metabolized by cytochrome CYP3A4. Close monitoring of serum sodium and volume status is necessary in patients receiving conivaptan.

\section{Acknowledgments}

Dr Li-Ng has no conflicts of interest to declare. Dr Verbalis is a consultant for Astellas Pharma US, Inc., Otsuka Pharmaceutical Co., Ltd, and Sanofi Aventis; has received funds 
for research from Yamanouchi Pharma America, Inc. and Astellas Pharma US, Inc; and has received fees for speaking from Astellas Pharma US, Inc.

\section{References}

1. Knepper MA. Molecular physiology of urinary concentrating mechanism: regulation of aquaporin water channels by vasopressin. Am J Physiol. 1997;272:F3-F12.

2. Fried LF, Palevsky PM. Hyponatremia and hypernatremia. Med Clin North Am. 1997;81:585-609.

3. Schwartz WB, Bennett W, Curelop S, Bartter FC. A syndrome of renal sodium loss and hyponatremia probably resulting from inappropriate secretion of antidiuretic hormone. Am J Med. 1957;23:529-542.

4. Verbalis JG. Vasopressin V2 receptor antagonists. J Mol Endocrinol. 2002;29:1-9.

5. Rai A, Whaley-Connell A, McFarlane S, et al. Hyponatremia, arginine vasopressin dysregulation, and vasopressin receptor antagonism. Am J Nephrol. 2006;26:579-589.

6. Upadhyay A, Jaber BL, Madias NE. Incidence and prevalence of hyponatremia. Am J Med. 2006;119(7 Suppl 1):S30-S35.

7. Vachharajani TJ, Zaman F, Abreo KD. Hyponatremia in critically ill patients. J Intensive Care Med. 2003;18:3-8.

8. Greenberg A, Verbalis JG. Vasopressin receptor antagonists. Kidney Int. 2006;69:2124-2130.

9. Vaprisol (conivaptan $\mathrm{HCl}$ injection). Package insert. Deerfield IL: Astellas Tokai Co.; February 2006.

10. Risvanis J, Naitoh M, Johnston CI, Burrell LM. In vivo and in vitro characterization of a nonpeptide vasopressin V1A and V2 receptor antagonist (YM087) in the rat. Eur J Pharmacol. 1999;381:23-30.

11. Burnier M, Fricker AF, Hayoz D, et al. Pharmacokinetic and pharmacodynamic effects of YM087, a combined V1/V2 vasopressin receptor antagonist in normal subjects. Eur J Clin Pharmacol. 1999; 55:633-637.

12. Decaux G. Long-term treatment of patients with inappropriate secretion of antidiuretic hormone by the vasopressin receptor antagonist conivaptan, urea, or furosemide. Am J Med. 2001;110:582-584.

13. Udelson JE, Smith WB, Hendrix GB, et al. Acute hemodynamic effects of conivaptan, a dual V1A and V2 vasopressin receptor antagonist, in patients with advanced heart failure. Circulation. 2001;104: 2417-2423.

14. Martinez-Castelao A. Conivaptan. Curr Opin Investig Drugs. 2002;3:89-95.

15. Gross P, Bisaha JG, Smith N. Conivaptan, a novel V1A and V2 antagonist, increases serum sodium and effective water clearance in patients with hyponatremia. Circulation. 2004;110(Suppl 3):723 [abstract 3345].

16. Ghali JK, Koren MJ, Tylor JR, et al; Conivaptan Study Group. Efficacy and safety of oral conivaptan: a V1A/V2 vasopressin receptor antagonist, assessed in a randomized, placebo-controlled trial in patients with euvolemic or hypervolemic hyponatremia. J Clin Endocrinol Metab. 2006;91:2145-2152.

17. Zeltser D, Rosansky S, van Rensburg H, Verbalis JG, Smith N; Conivaptan Study Group. Assessment of the efficacy and safety of intravenous conivaptan in euvolemic and hypervolemic hyponatremia. Am J Nephrol. 2007;27:447-457.

Core Evidence

\section{Publish your work in this journal}

Core Evidence is an international, peer-reviewed open-access journal evaluating the evidence underlying the potential place in therapy of drugs throughout their development lifecycle from preclinical to postlaunch. The focus of each review is to evaluate the case for a new drug or class in outcome terms in specific indications and patient Submit your manuscript here: http://www.dovepress.com/core-evidence-journal
18. Verbalis JG, Zeltser D, Smith N, Barve A, Andoh M. Assessment of the efficacy and safety of intravenous conivaptan in patients with euvolemic hyponatremia: subgroup analysis of a randomized, controlled study. Clin Endocrinol (Oxf). 2008;69:159-168.

19. Ghali JK, Verbalis JG, McNutt B. Efficacy and safety of the vasopressin-receptor antagonist conivaptan hydrochloride injection in hyponatremic patients with and without underlying heart failure. San Francisco, CA: Oral session presentation at Endocrine Society Annual Conference; June 2008.

20. Goldsmith SR, Francis GS, Cowley AW, et al. Increased plasma arginine vasopressin levels in patients with congestive heart failure. $J \mathrm{Am}$ Coll Cardiol. 1983;1:1385-1390.

21. Rouleau J-L, Packer M, Moye L, et al. Prognostic value of neurohumoral activation in patients with an acute myocardial infarction: effect of captopril. J Am Coll Cardiol. 1994;24:583-591.

22. Goldsmith SR. Efficacy and safety of conivaptan in acute decompensated heart failure: a dose-ranging pilot study. J Card Fail. 2006; 12(6)Suppl:S72.

23. Russell SD, Selaru P, Pyne DA, et al. Rationale for use of an exercise end point and design for the ADVANCE (A Dose evaluation of a Vasopressin ANtagonist in CHF patients undergoing Exercise) trial. Am Heart J. 2003;145:179-186.

24. Sterns RH, Cappuccio JD, Silver SM, Cohen EP. Neurologic sequelae after treatment of severe hyponatremia: a multicenter perspective. $J \mathrm{Am}$ Soc Nephrol. 1994;4:1522-1530.

25. Gheorghiade M, Gattis WA, O'Connor CM, et al. Effects of tolvaptan, a vasopressin antagonist, in patients hospitalized with worsening heart failure: a randomized controlled trial. JAMA. 2004;291:1963-1971.

26. Gheorghiade M, Konstam MA, Burnett JC Jr, et al; Efficacy of Vasopressin Antagonism in Heart Failure Outcome Study With Tolvaptan (EVEREST) Investigators. Short term clinical effects of tolvaptan, an oral vasopressin antagonist, in patients hospitalized for heart failure: the EVEREST Clinical Status Trials. JAMA. 2007;297:1332-1343.

27. Konstam MA, Gheorghiade M, Burnett JC Jr, et al; Efficacy of Vasopressin Antagonism in Heart Failure Outcome Study With Tolvaptan (EVEREST) Investigators. Effects of oral tolvaptan in patients hospitalized for worsening heart failure: the EVEREST Outcome Trial. JAMA. 2007;297:1319-1331.

28. Verbalis JG, Goldsmith SR, Greenberg A, Schrier RW, Sterns RH. Hyponatremia treatment guidelines 2007: expert panel recommendations. Am J Med. 2007;120:S1-S21.

29. Wong F, Blei AT, Blendis LM, Thuluvath PJ. A vasopressin receptor antagonist (VPA-985) improves serum sodium concentration in patients with hyponatremia: a multicenter, randomized, placebo-controlled trial. Hepatology. 2003;37:182-191.

30. Gerbes AL, Gulberg V, Gines P, et al; The VPA study group. Therapy of hyponatremia in cirrhosis with a vasopressin receptor antagonist: a randomized double-blind multicenter trial. Gastroenterology. 2003;124:933-939.

31. Schrier RW, Gross P, Gheorghiade M, et al. Tolvaptan, a selective oral vasopressin V2-receptor antagonist, for hyponatremia. $N$ Engl J Med. 2006;355:2099-2112.

32. Soupart A, Gross P, Legros JJ, et al. Successful long-term treatment of hyponatremia in syndrome of inappropriate antidiuretic hormone secretion with Satavaptan (SR-121463B), an orally active non-peptide vasopressin V2-receptor antagonist. Clin J Am Soc Nephrol. 2006; $1: 1154-1160$.

\section{Dovepress}

groups. The manuscript management system is completely online and includes a very quick and fair peer-review system, which is all easy to use. Visit http://www.dovepress.com/testimonials.php to read real quotes from published authors. 